\title{
ARTICLE XIV
}

(a) This Agreement shall enter into force upon signature by the original Members.

(b) States approved by the Executive Board for membership in accordance with Article $\mathrm{V}$ (b) may become Members by submitting an instrument of acceptance of this Agreement to the Executive Director, which shall become effective on the date of receipt by the Executive Director.

(c) This Agreement may be amended by written agreement of the original Members.

(d) This Agreement may be terminated or suspended by written agreement of the original Members.

\section{ARTICLE XV}

A Member may withdraw from this Agreement at any time by giving written notice of withdrawal to the Executive Director. The withdrawal shall become effective ninety days after receipt of the notice of withdrawal by the Executive Director.

AGREEMENT ON SUPPLY OF A LIGHT-WATER REACTOR PROJECT TO THE DEMOCRATIC PEOPLE'S REPUBLIC OF KOREA BETWEEN THE KOREAN PENINSULA ENERGY DEVELOPMENT ORGANIZATION AND THE GOVERNMENT OF THE DEMOCRATIC PEOPLE'S REPUBLIC OF KOREA

New York City, 15 December 1995

The Korean Peninsula Energy Development Organization (hereinafter referred to as 'KEDO') and the Government of the Democratic People's Republic of Korea (the Democratic People's Republic of Korea is hereinafter referred to as the 'DPRK'),

Recognizing that KEDO is an international organization to finance and supply a light-water reactor project (hereinafter referred to as the 'LWR project') to the DPRK as specified in the Agreed Framework between the United States of America and the Democratic People's Republic of Korea of October 21, 1994 (hereinafter referred to as the 'US-DPRK Agreed Framework'), 
Recognizing that the US-DPRK Agreed Framework and the June 13, 1995, USDPRK Joint Press Statement specify that the US will serve as the principal point of contact with the DPRK for the LWR project, and

Reaffirming that the DPRK shall perform its obligations under the relevant provisions of the US-DPRK Agreed Framework and shall accept the LWR project as specified in the June 13, 1995, US-DPRK Joint Press Statement,

Have agreed as follows:

\section{ARTICLE I}

SCOPE OF SUPPLY

1. KEDO shall provide the LWR project, consisting of two pressurized light-water reactor (LWR) units with two coolant loops and a generating capacity of approximately $1,000 \mathrm{MW}(\mathrm{e})$ each, to the DPRK on a turnkey basis. The reactor model, selected by KEDO, will be the advanced version of US-origin design and technology currently under production.

2. KEDO shall be responsible for the scope of supply for the LWR project, specified in Annex 1 to the Agreement. The DPRK shall be responsible for other tasks and items necessary for the LWR project, specified in Annex 2 to the Agreement.

3. The LWR project shall conform to a set of codes and standards equivalent to those of the IAEA and the US and applied to the reactor model referred to in paragraph 1 of this Article. The set of codes and standards shall apply to the design, manufacture, construction, testing, commissioning, and operation and maintenance of the LWR plants, including safety, physical protection, environmental protection, and storage and disposal of radioactive waste.

\section{ARTICLE II}

\section{TERMS OF REPAYMENT}

1. KEDO shall finance the cost of the tasks and items specified in Annex 1 to the Agreement to be repaid by the DPRK on a long-term, interest-free basis.

2. The amount to be repaid by the DPRK will be jointly determined by KEDO and the DPRK based on examination by each side of the technical description of the LWR project specified in the commercial supply contract for the LWR project, the fair and reasonable market value of the LWR project, and the contract price payable by KEDO to its contractors and subcontractors under the commercial supply contracts for the tasks and items specified in Annex 1 to the Agreement. With respect to the tasks and items specified in Annex 1 to the Agreement, the DPRK shall not be responsible for 
any additional costs, other than those that result from actions by the DPRK or from its failure to take actions for which it is responsible, in which case the repayment amount shall be increased by an amount jointly determined by KEDO and the DPRK, based on actual added cost to the LWR project payable by KEDO.

3. The DPRK shall repay KEDO for each LWR plant in equal, semiannual installments, free of interest, over a 20-year term after completion of each LWR plant. The DPRK may pay KEDO in cash, cash equivalents, or through the transfer of goods. In the event that the DPRK pays in cash equivalents or goods (such payment is hereinafter referred to as 'in-kind payment'), the value of such in-kind payment shall be determined jointly by KEDO and the DPRK, based on an agreed formula for determining fair and reasonable market price.

4. Details concerning the amount and terms of repayment shall be specified in a separate protocol between KEDO and the DPRK pursuant to the Agreement.

\section{ARTICLE III \\ DELIVERY SCHEDULE}

1. KEDO shall develop a delivery schedule for the LWR project aimed at achieving a completion date of 2003. The schedule of relevant steps to be performed by the DPRK under the US-DPRK Agreed Framework, as specified in Annex 3 to the Agreement, shall be integrated with the delivery schedule for the LWR project with the aim of achieving the performance of such steps by 2003 and the smooth implementation of the LWR project. As specified in the US-DPRK Agreed Framework, the provision of the LWR project and the performance of the steps specified in Annex 3 to the Agreement are mutually conditional.

2. For purposes of the Agreement, 'completion' of an LWR plant means completion of performance tests that is satisfactory in accordance with the set of codes and standards specified in Article I(3). Upon completion of each plant, the DPRK shall issue to KEDO a take-over certificate for each respective plant.

3. Details concerning the schedule for the delivery of the LWR project and the performance of the steps specified in Annex 3 to the Agreement, including mutually agreed procedures for any necessary changes and completion of a significant portion of the LWR project as specified in Annex 4 to the Agreement, shall be specified in a separate protocol between KEDO and the DPRK pursuant to the Agreement.

ARTICLE IV

IMPLEMENTING ARRANGEMENTS

1. The DPRK may designate a DPRK firm as its agent and authorize the firm to enter into implementing arrangements as necessary to facilitate the LWR project. 
2. KEDO shall select a prime contractor to carry out the LWR project and shall conclude a commercial supply contract with this prime contractor. A US firm will serve as program coordinator to assist KEDO in supervising overall implementation of the LWR project, and KEDO will select the program coordinator.

3. KEDO and the DPRK shall facilitate practical arrangements that both sides deem necessary, including efficient contacts and cooperation among the participants in the LWR project, to ensure the expeditious and smooth implementation of the LWR project.

4. Written communications required for the implementation of the Agreement may be executed in the English or Korean language. Existing documents and data may be used or transmitted in their original languages.

5. KEDO, its contractors and subcontractors shall be permitted to operate offices at the project site and other directly related locations such as the nearby port or airport as shall be agreed between KEDO and the DPRK, as the progress of the LWR project may require.

6. The DPRK shall recognize KEDO's independent juridical status and shall accord KEDO and its staff such privileges and immunities in the territory of the DPRK as necessary to carry out the functions entrusted to KEDO. KEDO's juridical status and privileges and immunities shall be specified in a separate protocol between KEDO and the DPRK pursuant to the Agreement.

7. The DPRK shall take steps to protect the safety of all personnel sent to the DPRK by KEDO, its contractors and subcontractors, and their respective property. Appropriate consular protection in conformity with established international practice shall be allowed for all such personnel. Necessary consular arrangements shall be specified in a separate protocol between KEDO and the DPRK pursuant to the Agreement.

8. KEDO shall take steps to ensure that all personnel sent to the DPRK by KEDO, its contractors and subcontractors shall undertake to respect the relevant laws of the DPRK, as shall be agreed between KEDO and the DPRK, and to conduct themselves at all times in a decent and professional manner.

9. The DPRK shall not interfere with the repatriation, in accordance with customs clearance procedures, by KEDO, its contractors and subcontractors of construction equipment and remaining materials from the LWR project.

10. The DPRK shall seek recovery solely from the property and assets of KEDO for the satisfaction of any claims arising under the Agreement or from any of the acts and ommissions, liabilities, or obligations of KEDO, its contractors and subcontractors 
in direct connection with the Agreement, protocols and contracts pursuant to the Agreement.

\author{
ARTICLE V \\ SITE SELECTION AND STUDY
}

1. KEDO shall conduct a study of the preferred Kumho area near Sinpo City, South Hamgyong Province to ensure that the site satisfies appropriate site selection criteria as shall be agreed between KEDO and the DPRK and to identify the requirements for construction and operation of the LWR plants, including infrastructure improvements.

2. To facilitate this study, the DPRK shall cooperate and provide KEDO with access to the relevant available information, including the results of the studies that were performed previously at this site. In the event that such data is not sufficient, KEDO shall make arrangements to obtain additional information or to conduct the necessary site studies.

3. Details concerning site access and the use of the site shall be specified in a separate protocol between KEDO and the DPRK pursuant to the Agreement.

\title{
ARTICLE VI \\ QUALITY ASSURANCE AND WARRANTIES
}

1. KEDO shall be responsible for design and implementation of a quality assurance program in accordance with the set of codes and standards specified in Article I(3). The quality assurance program shall include appropriate procedures for design, materials, manufacture and assembly of equipment and components, and quality of construction.

2. KEDO shall provide the DPRK with appropriate documentation on the quality assurance program, and the DPRK shall have the right to participate in the implementation of the quality assurance program, which will include appropriate inspections, tests, commissioning and review by the DPRK of the results thereof.

3. KEDO shall guarantee that the generating capacity of each LWR plant at the time of completion, as defined in Article III(2), will be approximately 1,000 MW(e). KEDO shall guarantee that the major components provided by relevant contractors and subcontractors will be new and free from defects in design, workmanship, and material for a period of two years after completion, but in no event longer than five years after the date of shipment of such major components. The LWR fuel for the initial loading for each LWR plant shall be guaranteed in accordance with standard nuclear industry practice. KEDO shall guarantee that the civil construction work for the LWR project will be free of defects in design, workmanship, and material for a period of two years after completion. 
4. Details concerning the provisions of this Article and the content and procedures for issuance and receipt of warranties shall be specified in a separate protocol between KEDO and the DPRK pursuant to the Agreement.

\section{ARTICLE VII \\ TRAINING}

1. KEDO shall design and implement a comprehensive training program in accordance with standard nuclear industry practice for the DPRK's operation and maintenance of the LWR plants. Such training shall be held at mutually agreeable locations as soon as practicable. The DPRK shall be responsible for providing a sufficient number of qualified candidates for this program.

2. Details concerning the training program shall be specified in a separate protocol between KEDO and the DPRK pursuant to the Agreement.

\section{ARTICLE VIII \\ OPERATION AND MAINTENANCE}

1. KEDO shall assist the DPRK to obtain LWR fuel, other than that provided pursuant to Annex 1 to the Agreement, through commercial contracts with a DPRKpreferred supplier for the useful life of the LWR plants.

2. KEDO shall assist the DPRK to obtain spare and wear parts, consumables, special tools, and technical services for the operation and maintenance of the LWR plants, other than those provided pursuant to Annex 1 to the Agreement, through commercial contracts with a DPRK-preferred supplier for the useful life of the LWR plants.

3. KEDO and the DPRK shall cooperate to ensure the safe storage and disposition of the spent fuel from the LWR plants. If requested by KEDO, the DPRK shall relinquish any ownership rights over the LWR spent fuel and agree to the transfer of the spent fuel out of its territory as soon as technically possible after the fuel is discharged, through appropriate commercial contracts.

4. Necessary arrangements for the transfer of LWR spent fuel out of the DPRK shall be specified in a separate protocol between KEDO and the DPRK pursuant to the Agreement.

\section{ARTICLE IX SERVICES}

1. The DPRK shall process for approval all applications necessary for completion of the LWR project expeditiously and free of charge. These approvals shall include all 
permits issued by the DPRK nuclear regulatory authority, customs clearance, entry and other permits, licenses, site access rights, and site take-over agreements. In the event that any such approval is delayed beyond the normally required time or denied, the DPRK shall notify KEDO promptly of the reasons therefor, and the schedule and cost for the LWR project may be adjusted as appropriate.

2. KEDO, its contractors and subcontractors, and their respective personnel shall be exempt from DPRK taxes, duties, charges and fees as shall be agreed between KEDO and the DPRK, and expropriation in connection with the LWR project.

3. All personnel sent to the DPRK by KEDO, its contractors and subcontractors shall be allowed unimpeded access to the project site and to appropriate and efficient transportation routes, including air and sea links, to and from the project site as designated by the DPRK and agreed between KEDO and the DPRK. Additional routes will be considered as the progress of the LWR project may require.

4. The DPRK shall, to the extent possible, make available at a fair price port services, transportation, labor, potable water, food, off-site lodging and offices, communications, fuel, electrical power, materials, medical services, currency exchanges and other financial services, and other amenities necessary for living and working by personnel sent to the DPRK by KEDO, its contractors and subcontractors.

5. KEDO, its contractors and subcontractors, and their respective personnel shall be allowed unimpeded use of available means of communications in the DPRK. In addition, KEDO, its contractors and subcontractors shall be permitted by the DPRK to establish secure and independent means of communications for their offices, based on a timely and case-by-case review of equipment requests and in accordance with relevant telecommunications regulations of the DPRK.

6. Details concerning the above-referenced services shall be specified, as appropriate, in one or more separate protocols between KEDO and the DPRK pursuant to the Agreement.

\section{ARTICLE X}

NUCLEAR SAFETY AND REGULATION

1. KEDO shall be responsible for assuring that design, manufacture, construction, testing, and commissioning of the LWR plants are in compliance with nuclear safety and regulatory codes and standards specified in Article I(3).

2. . . .

3. The DPRK shall be responsible for the safe operation and maintenance of the LWR plants, appropriate physical protection, environmental protection, and, consistent 
with Article VIII(3), the safe storage and disposal of radioactive waste, including spent fuel, in conformity with the set of codes and standards specified in Article I(3). In this regard, the DPRK shall assure that appropriate nuclear regulatory standards and procedures are in place to ensure the safe operation and maintenance of the LWR plants.

4. Prior to the shipment of any fuel assemblies to the DPRK, the DPRK shall observe the provisions set forth in the Convention on Nuclear Safety (done at Vienna, September 20, 1994), the Convention on Early Notification of a Nuclear Accident (adopted at Vienna, September 26, 1986), the Convention on Assistance in the Case of a Nuclear Accident or Radiological Emergency (adopted at Vienna, September 26, 1986), and the Convention on the Physical Protection of Nuclear Material (opened for signature at Vienna and New York, March 3, 1980).

5. After the completion of the LWR plants, KEDO and the DPRK shall conduct safety reviews to ensure the safe operation and maintenance of the LWR plants. In this regard, the DPRK shall provide necessary assistance to enable such reviews to be conducted as expeditiously as possible and shall give due consideration to the results of such reviews. Details concerning the schedule and procedures for conducting the safety reviews shall be specified in a separate protocol between KEDO and the DPRK pursuant to the Agreement.

6. In the event of a nuclear emergency or accident, the DPRK shall permit immediate access to the site and information by personnel sent by KEDO, its contractors and subcontractors to determine the extent of safety concerns and to provide safety assistance.

\section{ARTICLE XI \\ NUCLEAR LIABILITY}

1. The DPRK shall ensure that a legal and financial mechanism is available for meeting claims brought within the DPRK for damages in the event of a nuclear incident (as defined in the Vienna Convention on Civil Liability for Nuclear Damage, done at Vienna, May 21, 1963) in connection with the LWR plants. The legal mechanism shall include the channeling of liability in the event of a nuclear incident to the operator on the basis of absolute liability. The DPRK shall ensure that the operator is able to satisfy such liabilities.

2. Prior to the shipment of any fuel assemblies to the DPRK, the DPRK shall enter into an indemnity agreement with KEDO, and shall secure nuclear liability insurance or other financial security to protect KEDO, its contractors and subcontractors, and their respective personnel in connection with any third party claims in any court or forum arising from activities undertaken pursuant to the Agreement in the event of nuclear damage or loss occurring inside or outside the territory of the DPRK as a result 
of a nuclear incident in connection with the LWR plants. Details concerning the indemnity agreement and insurance or other financial security shall be specified in a separate protocol between KEDO and the DPRK pursuant to the Agreement.

3. The DPRK shall bring no claims against KEDO, its contractors and subcontractors, and their respective personnel arising out of any nuclear damage or loss.

4. This Article shall not be construed as acknowledging the jurisdiction of any court or forum or as waiving any immunity of either side.

5. The domestic legal system of the DPRK may provide that, if the operator proves that the nuclear damage resulted wholly or partly either from the gross negligence of the person suffering the damage or from an act or omission of such person done with intent to cause damage, the operator may be relieved wholly or partly from his obligation to pay compensation in respect of the damage suffered by such person. The operator shall have a right of recourse only if the damage caused by a nuclear incident results from an act or omission done with intent to cause damage, against the individual acting or omitting to act with such intent. For purposes of this paragraph, the terms 'person' and 'individual' shall have the same meaning as in the Vienna Convention on Civil Liability for Nuclear Damage (done at Vienna, May 21, 1963).

\section{ARTICLE XII}

INTELLECTUAL PROPERTY

1. In the course of performing its obligations under the Agreement, each side may receive, directly or indirectly, information relating to the intellectual property of the other side. All such information and any materials or documents containing such information (collectively, the 'Intellectual Property') are proprietary and confidential to such other side, whether or not protected by patent or copyright law. Each side agrees to protect the confidentiality of the other side's Intellectual Property and to use it only for the purposes of the LWR project as provided for in the Agreement and in accordance with international norms, including practices established by the Paris Convention on the Protection of Industrial Property Rights.

2. Except as otherwise agreed between the two sides, neither side shall replicate, copy, or otherwise reproduce any of the equipment or technology of the other side provided in connection with the LWR project.

\section{ARTICLE XIII ASSURANCES}

1. The DPRK shall use the reactors, technology, and nuclear material (as defined in accordance with international practice) transferred pursuant to the Agreement, as 
well as any nuclear mateRial used therein or produced through the use of such items, exclusively for peaceful, non-explosive purposes.

2. The DPRK shall ensure that the reactors, technology, and nuclear material transferred pursuant to the Agreement, as well as any nuclear material used therein or produced through the use of such items, are used properly and exclusively for the purposes of the LWR project.

3. The DPRK shall provide effective physical protection in accordance with international standards with respect to the reactors and nuclear material transferred pursuant to the Agreement, as well as any nuclear material used therein or produced through the use of such items for the useful life of such reactors and nuclear material.

4. The DPRK shall apply IAEA safeguards to the reactors and nuclear material transferred pursuant to the Agreement, as well as any nuclear material used therein or produced through the use of such items, for the useful life of such reactors and nuclear material.

5. The DPRK shall at no time reprocess or increase the enrichment level of any nuclear material transferred pursuant to the Agreement, or any nuclear material used in or produced through the use of any reactor or nuclear material transferred in the LWR project.

6. The DPRK shall not transfer any nuclear equipment or technology or nuclear material transferred pursuant to the Agreement, or any nuclear material used therein or produced through the use of such items, outside the territory of the DPRK unless otherwise agreed between KEDO and the DPRK, except as provided for in Article VIII(3).

7. The above-referenced assurances may be supplemented by DPRK assurances, through appropriate arrangements, to KEDO members that provide to the DPRK any components controlled under the Export Trigger List of the Nuclear Suppliers Group for the LWR project, if and when such KEDO member or members and the DPRK deem it necessary.

\section{ARTICLE XIV}

FORCE MAJEURE

Either side's performance shall be considered excusably delayed if such delay is due to one or more events that are internationally accepted to constitute force majeure. Each such event is herein referred to as an event of 'Force Majeure'. The side whose performance is delayed by an event of Force Majeure shall provide notice of such delay to the other side promptly after such event has occurred and shall use such efforts as are reasonable in the circumstances to mitigate such delay and the effect thereof on 
such side's performance. The two sides shall then consult with each other promptly and in good faith to determine whether alternative performance and the adjustment of the schedule and cost of the LWR project are necessary.

\section{ARTICLE XV \\ DISPUTE RESOLUTION}

1. Any disputes arising out of the interpretation or implementation of the Agreement shall be settled through consultations between KEDO and the DPRK, in conformity with the principles of international law. KEDO and the DPRK shall organize a coordinating committee composed of three people from each side to help settle disputes that may arise in the process of implementing the Agreement.

2. Any dispute that cannot be resolved in this manner shall, at the request of either side and with the consent of the other side, be submitted to an arbitral tribunal composed as follows: KEDO and the DPRK shall each designate one arbitrator, and the two arbitrators so designated shall elect a third, who shall be the Chairman. If, within thirty days of the mutual agreement for arbitration, either KEDO or the DPRK has not designated an arbitrator, either KEDO or the DPRK may request the President of the International Court of Justice to appoint an arbitrator. The same procedure shall apply if, within thirty days of the designation or appointment of the second arbitrator, the third arbitrator has not been elected. A majority of the members of the arbitral tribunal shall constitute a quorum, and all decisions shall require the concurrence of two arbitrators. The arbitral procedure shall be fixed by the tribunal. The decisions of the tribunal shall be binding on KEDO and the DPRK. Each side shall bear the cost of its own arbitrator and its representation in the arbitral proceedings. The cost of the Chairman in discharging his duties and the remaining costs of the arbitral tribunal shall be borne equally by both sides.

\section{ARTICLE XVI \\ ACTIONS IN THE EVENT OF NONCOMPLIANCE}

1. KEDO and the DPRK shall perform their respective obligations in good faith to achieve the basic objectives of the Agreement.

2. In the event that either side fails to take its respective steps specified in the Agreement, the other side shall have the right to require the immediate payment of any amounts due and financial losses in connection with the LWR project.

3. In the event of late payment or nonpayment by either side with respect to financial obligations to the other side incurred in implementing the Agreement, the other side shall have the right to assess and apply penalties against that side. Details concerning the assessment and application of such penalties shall be specified in a separate protocol between KEDO and the DPRK pursuant to the Agreement. 
ARTICLE XVII

AMENDMENTS

1. The Agreement may be amended by written agreement between the two sides.

2. Any amendment shall enter into force on the date of its signature.

\section{ARTICLE XVIII \\ ENTRY INTO FORCE}

1. The Agreement shall constitute an international agreement between KEDO and the DPRK, and shall be binding on both sides under international law.

2. The Agreement shall enter into force on the date of its signature.

3. The Annexes to the Agreement shall be an integral part of the Agreement.

4. The protocols pursuant to the Agreement shall enter into force on the date of their respective signature.

[The text of Annexes 1,2 and 4 are not reproduced]

\section{ANNEX 3}

The relevant steps to be performed by the DPRK in connection with the supply of the LWR project under the US-DPRK Agreed Framework, as referenced in Article III(1) of the Agreement, consist of the following:

1. The DPRK will remain a party to the Treaty on the Non-Proliferation of Nuclear Weapons and will allow implementation of its safeguards agreement under the Treaty, as specified in the US-DPRK Agreed Framework.

2. The DPRK will continue the freeze on its graphite-moderated reactors and related facilities and provide full cooperation to the IAEA in its monitoring of the freeze.

3. The DPRK will refrain from the construction of new graphite-moderated reactors and related facilities.

4. In the event that US firms will be providing any key nuclear components, the US and the DPRK will conclude a bilateral agreement for peaceful nuclear cooperation prior to the delivery of such components. Such agreement will not be implemented until a significant portion of the LWR project is completed, as specified in Annex 4 to the Agreement. For purposes of the Agreement, 'key nuclear components' are 
the components controlled under the Export Trigger List of the Nuclear Suppliers Group.

5. The DPRK will continue cooperation on safe storage and ultimate disposition of spent fuel from the $5 \mathrm{MW}(\mathrm{e})$ experimental reactor.

6. Upon the signing of the Agreement, the DPRK will permit resumption of ad hoc and routine inspections under the DPRK's safeguards agreement with the IAEA with respect to facilities not subject to the freeze.

7. When a significant portion of the LWR project is completed, but before delivery of key nuclear components, the DPRK will come into full compliance with its IAEA safeguards agreement, including taking all steps that may be deemed necessary by the IAEA.

8. When the first LWR plant is completed, the DPRK will begin dismantlement of its frozen graphite-moderated reactors and related facilities, and will complete such dismantlement when the second LWR plant is completed.

9. When delivery of the key nuclear components for the first LWR plant begins, the transfer from the DPRK of spent fuel from the $5 \mathrm{MW}(\mathrm{e})$ experimental reactor for ultimate disposition will begin and will be completed when the first LWR plant is completed. 